\title{
Conventional disease-modifying agents in rheumatoid arthritis - a review of their current use and role in treatment algorithms
}

\author{
Ivan Padjen, Mirna Reihl Crnogaj, Branimir Anić
}

Division of Clinical Immunology and Rheumatology, Department of Internal Medicine, University Hospital Centre Zagreb

and University of Zagreb, School of Medicine, Zagreb, Croatia

\begin{abstract}
Despite the development of targeted therapies, conventional synthetic disease-modifying antirheumatic drugs (cSDMARDs) remain the cornerstone of treatment of rheumatoid arthritis (RA). A literature search was conducted on treatment recommendations and relevant papers regarding new insights on therapeutics in rheumatoid arthritis. Methotrexate is considered the "anchor drug" due to its high efficacy as monotherapy and in combination with other conventional and targeted agents. Leflunomide and sulfasalazine are sound alternatives, whereas (hydroxy)chloroquine is primarily used in combination with other csDMARDs.

Their use is encouraged in all treatment phases - in combination with targeted agents, and with other csDMARDs. Combining different cSDMARDs is especially attractive in lower income settings given the evidence proving (almost) equal efficacy and safety of the CSDMARD combination approach compared to the combination of targeted agents with a cSDMARD.

The aim of this review is to provide a clinically oriented insight into the pharmacology of each cSDMARD and their place in treatment algorithms.
\end{abstract}

Key words: methotrexate, rheumatoid arthritis, leflunomide, disease-modifying antirheumatic drug.

\section{Introduction}

Rheumatoid arthritis (RA) is a disorder marked by chronic immune-mediated inflammation. Although it can affect a variety of tissues, the hallmark of the disease is synovitis with consequent destruction of the hyaline cartilage and the subchondral bone. Classically, the latter is detected on standard radiographs as joint space narrowing and bone erosions.

Despite the fact that rheumatoid arthritis may affect a variety of tissues and lead to premature atherosclerosis and increased cardiovascular morbidity and mortality, development of new joint space narrowing and bone erosions (also termed radiographic progression) can be detected much earlier in the course of the disease, even within the first months following disease onset [1].

Thus, prevention of radiographic progression is considered the key therapeutic goal in rheumatoid arthritis. To this end, the term "disease modification" has been coined specifically in the context of RA, referring to the property of an anti-inflammatory disease-modifying antirheumatic drug (DMARD) to inhibit radiographic progression [2]. Other clinically important actions of DMARDs include improvement of signs and symptoms, disease activity and functional status.

Prior to the advent of targeted therapies (biologicals and the more recently developed targeted synthetic molecules) disease-modifying effects had been observed with the use of several agents including methotrexate, leflunomide, sulfasalazine, antimalarials and the now mostly obsolete gold salts.

In that pre-biological era, these drugs were the first agents approved for RA and were labeled simply "DMARDs". They have recently been relabeled/reclassified as conventional synthetic DMARDs (csDMARDs), in contrast to targeted DMARDs, which encompass an increasingly expanding group of biologic and targeted synthetic agents [3]. 
The term "conventional" refers to the fact that the observation of a drug's clinical efficacy preceded the in-depth insight into its mechanism of action, which still seems to be only partially known for most of the csDMARDs.

In contrast to targeted DMARDs, csDMARDs were not designed with the intention to act against a specific molecule (the molecular target) involved in the inflammatory pathway relevant to the disease [3].

Although conventional synthetic DMARDs are not in the limelight of recent treatment developments in RA, they are still the first line of therapy, the most prescribed and, what is globally important, the least expensive treatment of rheumatoid arthritis.

The aim of this review is to provide an overview of the currently used csDMARDs and their role and place in the contemporary treatment algorithms.

\section{Methotrexate}

Methotrexate is the most widely used CSDMARD in rheumatoid arthritis. It is commonly referred to as the "anchor drug", having in mind the following two points:

- it is the first cSDMARD of choice in RA treatment algorithms and

- its use is highly recommended even after treatment with a targeted agent has been commenced [4, 5].

In addition to its effect on disease activity, symptoms and signs, physical function and radiographic progression, methotrexate has also been shown to improve survival of RA patients, primarily by decreasing cardiovascular mortality [6].

Methotrexate is a structural analogue of folate; hence it interferes with the role of folate in the synthesis of purine and pyrimidine nucleosides. This mechanism explains the drug's anti-proliferative effects relevant to its use in the treatment of malignancies and to the development of some of the drug-related adverse events.

However, the anti-inflammatory (and also antiatherogenic) effects seem to be mediated via other pathways, the most relevant of which may be activation of aminoimidazole carboxamide nucleotide (AICAR) transformylase, leading to increased levels of adenosine (Table I).

In contrast to high doses required in the treatment of malignant neoplasms, anti-inflammatory effects of methotrexate occur at much lower doses commonly used in the treatment of RA and other rheumatic diseases [7].

Methotrexate is administered in a weekly oral or subcutaneous regimen at a dose that should be rapidly escalated from the initial 7.5-12.5 mg to a weekly dose of about $0.3 \mathrm{mg} / \mathrm{kg}$ (20-25 mg per week would be the optimal therapeutic dose in the Western hemisphere) [5].
The subcutaneous route and split oral administration (i.e. divided into two doses on the same day of the week) may be associated with its greater bioavailability when the weekly dose exceeds $15 \mathrm{mg}$, and possibly also with a lower rate of gastrointestinal intolerance [8-10].

Folic acid is commonly co-administered to reduce the frequency of side effects, usually at a dose of $5 \mathrm{mg}$ weekly, on the second day following methotrexate. Importantly, it does not interfere with the anti-inflammatory actions of methotrexate.

As indicated above, methotrexate continues to serve as the first drug of choice in the treatment of rheumatoid arthritis. In patients with early rheumatoid arthritis, low disease activity is achieved with methotrexate monotherapy in up to $25 \%$ patients after 6 months of treatment, and in an even higher proportion when used with low-dose glucocorticoids.

This success rate is similar to most of the targeted agents currently used in the treatment of RA, except for tocilizumab and Janus kinase inhibitors, which have demonstrated efficacy superior to methotrexate [11-13]. Intriguingly, methotrexate was used at a suboptimal dose in most of the trials comparing its efficacy with the efficacy of targeted agents [14].

When used as monotherapy, no other csDMARD has been shown to have greater efficacy than methotrexate. Of all currently used cSDMARDs, only leflunomide and sulfasalazine have demonstrated efficacy similar to that of methotrexate; however, this statement should be taken with caution since it is based on evidence from older trials where methotrexate was used at doses lower than those currently recommended [15].

Apart from being used as monotherapy, methotrexate can be used in combination with other csDMARDs or with a targeted agent [5]. Given that both methotrexate and its metabolites are excreted via the kidney, the dose should be adjusted in patients with renal insufficiency and geriatric patients [16].

Methotrexate is generally contraindicated in the setting of an acute systemic infection, ongoing herpes zoster, interstitial pneumonitis/clinically significant pulmonary fibrosis, moderate to severe cytopenia, severe hepatic or renal impairment, pregnancy and breastfeeding [17]. It should be withdrawn at least 1-3 months prior to conception [18].

In a systematic review of 21 prospective studies (involving 3463 patients), adverse events were observed in $72.9 \%$ of patients treated with methotrexate. However, they were mild and associated with a relatively low rate of drug withdrawal due to toxicity, 10-37\%, which was lower than for sulfasalazine (17-52\%) and higher than for hydroxychloroquine (10-14\%). 
Table I. Pharmacological properties of the four conventional synthetic disease-modifying antirheumatic drugs used in the treatment of rheumatoid arthritis

\begin{tabular}{|c|c|c|c|c|}
\hline Parameters & Methotrexate & Leflunomide & Sulfasalazine & $\begin{array}{l}\text { Hydroxychloroquine/ } \\
\text { chloroquine }\end{array}$ \\
\hline $\begin{array}{l}\text { Proposed } \\
\text { mechanism(s) } \\
\text { of action }\end{array}$ & $\begin{array}{l}\text { Interference with } \\
\text { nucleoside synthesis } \\
\text { (anti-proliferative); } \\
\text { increase of adenosine } \\
\text { levels (anti- } \\
\text { inflammatory) }\end{array}$ & $\begin{array}{l}\text { Inhibition of } \\
\text { dihydroorotate } \\
\text { dehydrogenase } \\
\text { (DHOOH), thus } \\
\text { blocking the synthesis } \\
\text { of pyrimidine }\end{array}$ & $\begin{array}{l}\text { Not fully understood; } \\
\text { sulfasalazine and } \\
\text { its metabolite } \\
\text { sulfapyridine found } \\
\text { in the synovial fluid }\end{array}$ & $\begin{array}{l}\text { Not fully understood; } \\
\text { stabilization of lysosomes, } \\
\text { regulation of cytokine } \\
\text { production, antigen } \\
\text { presentation, beneficial } \\
\text { metabolic effects, etc. }\end{array}$ \\
\hline Dosage & $\begin{array}{l}\text { Up to } 20-25 \text { mg } \\
\text { weekly; usually with } \\
5 \text { mg of folic acid } \\
\text { once weekly }\end{array}$ & Up to $20 \mathrm{mg}$ daily & $\begin{array}{l}\text { Up to } 3 \text { g daily; folate } \\
\text { co-administration } \\
\text { during pregnancy }\end{array}$ & $\begin{array}{l}200 \text { mg (up to } \\
400 \text { mg) daily for } \\
\text { hydroxychloroquine; } \\
250 \text { mg daily for } \\
\text { chloroquine }\end{array}$ \\
\hline $\begin{array}{l}\text { Route } \\
\text { of administration }\end{array}$ & Oral, subcutaneous & Oral & Oral & Oral \\
\hline $\begin{array}{l}\text { Control of disease } \\
\text { activity }\end{array}$ & Yes & Yes & Yes & No (evidence insufficient) \\
\hline $\begin{array}{l}\text { Control of radiographic } \\
\text { progression }\end{array}$ & Yes & Yes & Yes & No (evidence insufficient) \\
\hline $\begin{array}{l}\text { Compatible with } \\
\text { pregnancy and } \\
\text { breastfeeding }\end{array}$ & No & No & Yes & Yes \\
\hline Contraindications & $\begin{array}{c}\text { Acute systemic } \\
\text { infection, herpes } \\
\text { zoster, interstitial } \\
\text { pneumonitis/ } \\
\text { fibrosis, moderate- } \\
\text { severe cytopenia, } \\
\text { severe hepatic/renal } \\
\text { insufficiency }\end{array}$ & As for methotrexate & $\begin{array}{l}\text { Allergy to salicylates } \\
\text { and sulfonamides; } \\
\text { thrombocytopenia, } \\
\text { acute viral hepatitis, } \\
\text { severe liver } \\
\text { disease, deficiency } \\
\text { of 6-phosphate } \\
\text { dehydrogenase }\end{array}$ & $\begin{array}{c}\text { Moderate to severe retinal } \\
\text { disease }\end{array}$ \\
\hline $\begin{array}{l}\text { Most important } \\
\text { adverse events }\end{array}$ & $\begin{array}{c}\text { Gastrointestinal } \\
\text { intolerance, increased } \\
\text { liver transaminases; } \\
\text { cytopenia, } \\
\text { hypersensitive } \\
\text { pneumonitis (rare) }\end{array}$ & $\begin{array}{c}\text { Gastrointestinal } \\
\text { intolerance, increased } \\
\text { liver transaminases, } \\
\text { arterial hypertension, } \\
\text { distal axonal } \\
\text { polyneuropathy }\end{array}$ & $\begin{array}{c}\text { Nausea, } \\
\text { gastrointestinal } \\
\text { intolerance, non- } \\
\text { specific neurologic } \\
\text { symptoms, rash, } \\
\text { increased liver } \\
\text { transaminases, } \\
\text { cytopenia }\end{array}$ & $\begin{array}{l}\text { Irreversible retinopathy, } \\
\text { gastrointestinal and } \\
\text { neuromuscular events }\end{array}$ \\
\hline
\end{tabular}

Gastrointestinal intolerance was the most frequently observed group of adverse events (30.8\%), comprising stomatitis, oral ulcers, abdominal pain, nausea, vomiting, dyspepsia, diarrhea, gastrointestinal bleeding and weight/appetite loss. Increased transaminase levels were the second most common adverse event, observed in $18.5 \%$ [19] (Table I).

Other adverse events described in patients on methotrexate include cytopenia, acute interstitial hypersensitive pneumonitis, liver cirrhosis, paradoxically accelerated nodulosis, rashes, non-specific central nervous system symptoms, flulike illness, teratogenicity and possibly also rare lymphomas associated with Epstein-Barr virus infection [19, 20]. The risk of (serious) infections does not seem to exceed the background risk observed in patients with rheumatoid arthritis [19].

\section{Leflunomide}

Leflunomide entered the market in 1998, the same year that the first biologicals agents, infliximab and etanercept, received their approval for rheumatoid arthritis. This may be the reason why leflunomide has not received as much attention as methotrexate, despite a similar efficacy and safety profile [15].

This can be illustrated by the fact that methotrexate, and not leflunomide, was almost exclusively used as the comparator csDMARD (gold standard) in trials of 
biologic and targeted synthetic agents in rheumatoid arthritis [14].

Nevertheless, leflunomide is most likely the best available csDMARD alternative to methotrexate for the treatment of RA and has been acknowledged as such by current treatment recommendations $[5,15]$.

Leflunomide is a prodrug exerting its immunomodulatory effects via its metabolite, A771726. The main molecular target of leflunomide is dihydroorotate dehydrogenase (DHODH), an enzyme involved in de novo synthesis of pyrimidines. Inhibition of this enzyme affects different arms of the immune system of pathogenic importance in RA, including T-cells, B-cells, activation and expression of nuclear factor (NF) kappa B, as well as the production of pro-inflammatory cytokines such as tumor necrosis factor $\alpha$ (TNF- $\alpha$ ) [21, 22] (Table I).

Although such an idea might be tempting, the fact of a known molecular target is not sufficient to classify leflunomide as a targeted synthetic DMARD (tsDMARD), because leflunomide was not developed a priori with the intention to inhibit DHODH, and the drug's molecular target was found later [3].

Leflunomide has established its role as an alternative to methotrexate - as monotherapy in patients with a contraindication to methotrexate or after methotrexate failure, provided that biological therapy is not indicated or not available [5].

Similar to methotrexate, leflunomide has been shown to induce DAS28 remission (corresponding to low disease activity according to current standards) in 25\% of early RA patients in a prospective non-interventional study [23].

In addition to its use as monotherapy, leflunomide can also be administered in combination with other cSDMARDs and/or targeted agents [5].

The drug is available in its oral formulation and is prescribed at a usual daily dose of $20 \mathrm{mg}$. Previous practice of administering a loading dose (100 mg daily for three days) has been abandoned due to the lack of additional benefit and a slightly higher frequency of early adverse events including diarrhea and elevated liver enzymes [24]. The drug is metabolized in the gut wall and the hepatocytes, after which its metabolites undergo elimination - while urinary excretion predominates within the first four days, fecal excretion predominates afterwards.

Despite the plasma half-life of leflunomide being 11 days, its metabolites can be detected for a prolonged period of time (for months to years), owing to enterohepatic recycling and low hepatic clearance $[16,25]$.

This is the reason why wash-out procedures (using cholestyramine or activated charcoal) are advocated in patients on leflunomide who suddenly develop a contra- indication to the drug (e.g. pregnancy, severe infection) or a serious adverse event ascribable to the drug $[25,26]$.

Contraindications for methotrexate and leflunomide are almost identical $[17,26]$. Leflunomide is classically considered to be incompatible with pregnancy and lactation, owing to reports of adverse maternal and fetal outcomes associated with its use [17].

Current recommendations advocate a washout procedure and stopping the drug at least 6 months before a planned pregnancy and avoidance of the drug during both pregnancy and breastfeeding [18].

Although recent evidence from a large prospective cohort study did not confirm an association of leflunomide exposure during pregnancy and adverse pregnancy outcomes, such reassuring results should still be taken with caution due to the relatively small number of pregnant women exposed to leflunomide in the study (and consequently limited statistical power) [27].

Given the prolonged elimination of the drug, a reasonable approach would be to avoid leflunomide in women of childbearing age or at least in women planning pregnancy.

Most of the adverse events observed in patients on methotrexate have also been recorded in patients on leflunomide, with increased levels of liver enzymes (hepatotoxicity) and gastrointestinal intolerance being the most frequently observed (as in the case of methotrexate).

Two specific adverse events have more frequently been described in patients on leflunomide: aggravation of arterial hypertension and distal axonal polyneuropathy (Table I). The latter should be recognized early because a greater chance of recovery can be expected if the drug is withdrawn within 30 days following the onset of symptoms [26].

\section{Sulfasalazine}

Sulfasalazine was introduced into the RA therapeutic armamentarium in the late 1930s, as the first drug synthetized specifically for this disease. At the time of its introduction, the rationale for its use was its combined anti-inflammatory and anti-microbial actions, which were in line with the prevailing concept of RA being a disease triggered by an infectious agent.

Although the drug's popularity reached its peak in the 1980s (before methotrexate was acknowledged as the anchor drug), sulfasalazine still plays an important role in current treatment algorithms [16]. This is especially relevant for the early phases of treatment where sulfasalazine holds the same place as leflunomide, serving as an alternative to methotrexate [5].

Although sulfasalazine was shown to be as efficacious as methotrexate in an older systematic review of 
the (still) relevant literature, the $95 \%$ confidence interval of this comparison was much wider than for the comparison between methotrexate and leflunomide (-1.96-3.15 vs. $-0.12-0.30)$. This can be interpreted as being in favor of leflunomide compared to sulfasalazine monotherapy, as the (best) alternative to methotrexate [15].

Furthermore, sulfasalazine is more likely to be stopped due to adverse events than methotrexate and leflunomide $[28,29]$.

As in the case of leflunomide, sulfasalazine can be prescribed in combination with other DMARDs, both non-biological and biological [5]. It is worth noting that, according to data from the NOR-DMARD registry, patients treated with sulfasalazine as the first CSDMARD of choice generally had lower disease activity and were more often rheumatoid factor negative [29].

The mechanism of action of sulfasalazine is still not completely understood. Its two covalently bound components - 5-aminosalicylic acid and sulfapyridine - are released in the large bowel following the cleavage of sulfasalazine by enzymes of the gut microbiome. 5-aminosalicylic acid largely remains in the bowel, exerting its anti-inflammatory effects locally, which is a property exploited in the treatment of inflammatory bowel disease.

On the other hand, both sulfasalazine and sulfapyridine are absorbed and found in the synovial fluid, which is believed to be important for their effect in the treatment of rheumatoid arthritis. Although both sulfasalazine and sulfapyridine are eliminated via the kidney, sulfasalazine is excreted in its intact form while sulfapyridine undergoes acetylation in the liver [30].

Despite the fact that sulfasalazine had previously been prescribed in doses usually not higher than $2 \mathrm{~g}$ daily, the previous European League Against Rheumatism (EULAR) recommendations advocate a rapid dose escalation to a daily dose of up to $3 \mathrm{~g}[5,31]$ (Table I).

Similar to methotrexate but probably to a lesser extent, such high(-er) doses may be associated with folate deficiency [16]. For this reason, some authorities advocate co-administration of folic acid, which may be especially warranted during pregnancy, when the daily dose of sulfasalazine should probably not exceed $2 \mathrm{~g}$ [18].

Despite concerns about the side effects of sulfasalazine (and mesalazine) when used for the treatment of inflammatory bowel disease, sulfasalazine is generally considered a safe drug in rheumatoid arthritis. In contrast to methotrexate and leflunomide, its use is compatible with both pregnancy and lactation, making the drug an attractive option in women planning pregnancy [18].

Sulfasalazine is contraindicated in patients allergic to salicylates and sulfonamides. Moreover, it should be avoided in patients with thrombocytopenia, acute viral hepatitis, severe liver disease, deficiency of 6-phosphate-dehydrogenase and porphyria [16].

Most of the adverse events usually occur within the first months of treatment and are usually benign. Withdrawal due to adverse events was observed in about $25 \%$ of patients in randomized trials. Nausea was the most frequent event, which could be circumvented by gradually increasing the dose.

Other common adverse events included non-specific neurologic symptoms and gastrointestinal intolerance, which accounted for two thirds of adverse events (Table I).

Other, less commonly described events were rash (usually maculopapular pruritic, much less frequently Stevens-Johnson syndrome), increased liver enzymes, cytopenia (mostly leukopenia and neutropenia), pulmonary infiltrates with peripheral eosinophilia and reversible oligospermia [16, 30, 32].

\section{Antimalarials - hydroxychloroquine and chloroquine}

Two antimalarials, chloroquine and its derivative hydroxychloroquine, have been used in the treatment of RA since the 1950s. They are traditionally classified as CSDMARDs primarily due to their historical role as a first line treatment in the pre-methotrexate era, the time when successful control of disease activity and radiographic progression had been considered an unrealistic goal achieved in only a minority of patients [33].

Despite the fact that antimalarial monotherapy has demonstrated "moderate" efficacy in RA, having an impact on various indicators of disease activity (joint counts, patient-reported scores, the erythrocyte sedimentation rate and ACR20 response) in two meta-analyses, the observed effects are far from meeting the current standards of disease remission [15, 34].

In fact, there is no evidence proving efficacy of antimalarial monotherapy in controlling disease activity or preventing/inhibiting radiographic progression in $\mathrm{pa}$ tients with rheumatoid arthritis [35].

Nevertheless, antimalarials are still included in RA therapeutic algorithms, especially in very mild disease (with few or none of the adverse prognostic factors) and as adjunctive agents in combination with other DMARDs [5, 31].

Modes of action of hydroxychloroquine and chloroquine are still poorly understood and most of the proposed mechanisms are based on in vitro observations. They include stabilization of lysosomes, regulation of cytokine production, interference with antigen presentation and toll-like receptor activation, as well as protection of the cartilage [36]. 
Moreover, antimalarials have been shown to exhibit beneficial metabolic and anti-atherosclerotic effects, and to reduce the risk of thrombosis, owing to their interference with the binding of antiphospholipid- $\beta 2$-glicoprotein complexes to components of the cell membrane $[37,38]$.

These features are of primary relevance in patients with systemic lupus erythematosus (SLE), where antimalarials are of the same therapeutic importance as aspirin in the treatment of ischemic heart disease, due to their efficacy in prevention of lupus flares and inhibition of organ damage [38].

However, two recent systematic reviews have demonstrated that the beneficial metabolic effects of hydroxychloroquine, as well as its impact on prevention of cardiovascular events, may be of additional therapeutic value in patients with rheumatoid arthritis [6, 39].

These findings have strengthened the role of antimalarials (hydroxychloroquine, but it is reasonable to expect that the same applies to chloroquine) as adjunctive agents in combination with (more) potent csDMARDs.

Hydroxychloroquine is available in $200 \mathrm{mg}$ tablets, whereas chloroquine usually comes in $250 \mathrm{mg}$ tablets. Although some authorities advocate the standard dose of one tablet daily, in some patients such an approach may lead to underdosing since the dose of hydroxychloroquine should be $5 \mathrm{mg} / \mathrm{kg}$ and the dose of chloroquine $3 \mathrm{mg} / \mathrm{kg}[16]$ (Table I).

Both hydroxychloroquine and chloroquine are relatively safe, and their use is compatible both with pregnancy and lactation [18].

Hydroxychloroquine is preferred over chloroquine due to a lower risk of retinal toxicity, the most dreaded but relatively rare adverse event (occurring in $<2 \%$ in the first decade of use, rising to $20 \%$ after 20 years) [16] The toxic effects are believed to be mediated by binding of the drug to melanin in the retinal pigment epithelium (RPE).

Although retinopathy is not reversible, its early detection and withholding the drug before any evidence of RPE may prevent central visual loss. The American College of Ophthalmology has recently issued recommendations, advising annual retinal screening (after mandatory baseline screening) in the presence of any of the following major risk factors: drug dose higher than recommended, longer treatment duration ( $>5$ years usually defined as prolonged use), renal disease, concomitant use of tamoxifen and underlying retinal/macular disease. Older age and liver disease have been identified as additional risk factors for retinal toxicity [40].

Gastrointestinal and neuromuscular adverse events are more common, but usually mild and non-specific (Table I). Less frequently observed, but potentially serious adverse events include heart conduction disturbances, congestive heart failure and neuromyopathy of insidious onset [37].

\section{The role of disease-modifying antirheumatic drugs in current treatment algorithms}

\section{Combining conventional synthetic disease-modifying antirheumatic drugs}

According to the current European recommendations for the management of RA, addition of a second csDMARD ("step-up" approach) may be advised in patients without unfavorable prognostic factors, after failure of cSDMARD monotherapy (due to lacking efficacy and/or toxicity) and prior to institution of a targeted agent [5].

However, the recommendations also leave the option of switching to monotherapy with another CSDMARD, being in line with the BeSt study, in which similar outcomes were observed between a switch of monotherapy and a csDMARD step-up approach [5, 41].

Both options have been allowed in the newest update of the treatment guidelines issued by the American College of Rheumatology [42].

Of note, the onset of action of each csDMARD can be expected to occur not earlier than 2-3 months following the drug's institution, which often requires "bridging" with a shorter course of glucocorticoids, while waiting for the newly added cSDMARD to start exerting its therapeutic effect.

Combination csDMARD regimens, primarily based on combining methotrexate with one or two other agents (such as the popular "triple therapy" regimen, a combination of methotrexate with sulfasalazine and hydroxychloroquine), have been shown to be superior to CSDMARD monotherapy and, even more strikingly, as efficacious and safe as combinations of a biological agent with methotrexate in several randomized trials (extensively reviewed by Cannella and O'Dell [16], Sethi and O'Dell [43], and Zanwar et al. [44]).

These observations have been further strengthened by a recent Cochrane network meta-analysis of 158 trials, in which triple therapy was shown to be superior to methotrexate monotherapy and not different from the combination of methotrexate with any of the biological agents or tofacitinib (a targeted synthetic DMARD) in inducing the American College of Rheumatology (ACR)50 response (a composite outcome measure reflecting a decline in disease activity by $50 \%$ ). Interestingly, this was confirmed both in methotrexatenaïve patients and patients who failed to respond to methotrexate monotherapy [45]. 
The findings of this meta-analysis are similar to the results of another network meta-analysis of 33 studies. The only major exception to the conclusions of the previous network meta-analysis was that inadequate responders to methotrexate tended to achieve deeper ACR70 responses (a composite outcome measure reflecting improvement of disease activity by $70 \%$ ) to the combination of a TNF- $\alpha$ inhibitor and methotrexate at 6 months, when compared to triple therapy.

This relative superiority was confirmed neither with the use of other endpoints (other outcome measures) nor at other time points in the analysis (3 months, 1 year and 2 years following treatment initiation) [46].

The option of initiating treatment with a combination of two or three csDMARDs (in csDMARD-naive patients) is no longer explicitly recommended and prioritized in the current versions of the European recommendations and guidelines of the American College of Rheumatology (despite being included in the 2013 version of EULAR recommendations and the previous issue of ACR guidelines) due to potential concerns over CSDMARD combination toxicity and methodological concerns over trials comparing treatment with CSDMARD combinations and monotherapy, especially when used in treatment-naïve patients [5, 42, 47, 48].

On the other hand, a combined cSDMARD regimen seems to be a reasonable step between CSDMARD monotherapy and the initiation of a targeted agent: such an approach is both efficacious and cost-effective, especially given that access to the (still) expensive targeted agents is limited [45].

The latter has been clearly illustrated in a recent work by Bergstra et al. [49], who demonstrated a large discrepancy between the use of biological DMARDs across 12 countries (from < $1 \%$ in South Africa and India to $>45 \%$ in the United States, France, Ireland and Japan).

Therefore, regimens combining different csDMARDs may be justified especially in low/moderate-income settings, even irrespective of the presence of unfavorable prognostic factors [44].

When initiating a cSDMARD combination regimen, the potential benefit (i.e. control of disease activity) and risk (i.e. adverse events) of each potential csDMARD combination should be weighed carefully. The aforementioned "triple therapy" regimen has demonstrated its high efficacy with an acceptable safety profile $[16,43,44]$.

Although this combination seems to have a good effect (if not the best among CSDMARD combinations), taking three different medications concomitantly has been associated with low persistence [50].

The combination of leflunomide and methotrexate has been shown to be superior to methotrexate in controlling disease activity, although the use of this com- bination requires caution due to a higher likelihood of elevated liver enzymes [51, 52].

Apart from the "triple therapy" regimen, the addition of hydroxychloroquine/chloroquine to leflunomide and sulfasalazine does not seem to yield additional benefit to the efficacy of leflunomide or sulfasalazine monotherapy $[53,54]$.

Thus, the latter combinations seem to be the least favorable. An exception is the combination of methotrexate and hydroxychloroquine, where the antimalarial has been shown to increase the bioavailability of methotrexate [55].

\section{Combining conventional synthetic disease-modifying antirheumatic drugs with targeted agents}

Available evidence implemented in the current European recommendations and the guidelines issued by the American College of Rheumatology supports the combination of targeted agents (both biologicals and the more recently introduced Janus kinase inhibitors) with a cSDMARD (preferably methotrexate at a dose of at least 7.5-10 mg weekly) [5, 42].

In the case of biologic agents, the rationale for such an approach is superior efficacy of combination therapy compared to biologic monotherapy. Interestingly, such a benefit of cSDMARD co-therapy has not been as unequivocally demonstrated in the case of Janus kinase (JAK) inhibitors.

Baricitinib plus methotrexate combination therapy has shown similar ACR responses to baricitinib monotherapy, but with superior efficacy of combination therapy on radiographic progression [56].

On the other hand, tofacitinib combined with methotrexate seems to exceed the efficacy of tofacitinib monotherapy, although this observation is based on results obtained in a non-inferiority setting [57].

Intriguingly, recent experimental evidence suggests that cSDMARDs, primarily methotrexate and leflunomide, may exert at least some of their pharmacological effects by interfering with JAK-STAT signaling (methotrexate inhibiting JAK1 and JAK2, leflunomide inhibiting JAK3).

This may explain why the addition of methotrexate (a proposed JAK1/JAK2 inhibitor) demonstrated an additive effect only in patients treated with tofacitinib (JAK1/ JAK3 inhibitor), and not also in patients on baricitinib (JAK1/JAK2 inhibitor). In the case of tofacitinib, methotrexate-driven JAK2 inhibition may have served as an additional anti-inflammatory mechanism.

On the other hand, JAK-inhibiting properties of methotrexate may be redundant in the case of (co-)treatment with baricitinib [58]. Despite these tempting theoretical presumptions, there is no evidence suggesting that 
JAK/STAT inhibition represents a dominant mechanism of action of any of the cSDMARDs.

An argument against the latter dominant role is the csDMARDs' late onset of action (2-3 months), which is in stark contrast with the prompt onset of action of currently available JAK inhibitors.

\section{The use of disease-modifying antirheumatic drugs in selected comorbid conditions/scenarios}

The existing therapeutic algorithms and the choice of medication should be tailored according to the individual patient's comorbid conditions and specific clinical circumstances. The approach to the treatment with each drug in pregnant and breastfeeding patients has already been addressed in the previous text.

Specifically in the case of csDMARDs, the most noteworthy comorbid conditions include advanced chronic renal and hepatic failure, conditions necessitating dose adjustments or even drug discontinuation.

In patients with renal failure, sulfasalazine seems to be the cSDMARD of choice, requiring no dose adjustments. On the other hand, the dose of methotrexate should be halved or the drug even avoided in patients with a GFR $<50 \mathrm{ml} / \mathrm{min}$. The dose of antimalarials should also be reduced by $50 \%$ in patients with a GFR $<30 \mathrm{ml} / \mathrm{min}$ [59].

Although it has been reported that no dose modification of leflunomide is warranted in patients on dialysis, available evidence on the use of leflunomide in the context of advanced renal disease is still scarce [60].

While methotrexate and leflunomide should be avoided in patients with chronic liver failure, sulfasalazine and antimalarials can be administered at lower doses and with caution [61].

According to the current guidelines of the American College of Rheumatology, the decision to treat a patient with a single cSDMARD or a cSDMARD combination should not be influenced by a patient's history of hepatitis B or C infection, episodes of previous serious infections and previously treated malignancy (skin non-melanoma, melanoma, solid organ or lymphoproliferative).

In fact, csDMARD are preferred over TNF- $\alpha$ inhibitors in patients with congestive heart failure, hepatitis $C$ patients not receiving antiviral agents, patients with previous serious infections and those with a history of a previously treated lymphoproliferative condition.

Furthermore, csDMARDs are preferred over all targeted agents in patients with a history of skin cancer [42]. Due to a very low level of evidence backing these recommendations (with the exception of congestive heart failure), they should be taken with caution and probably implemented on a patient-by-patient basis.
Regarding cardiovascular comorbidities of patients treated with cSDMARDs, methotrexate and hydroxychloroquine have been shown to reduce the cardiovascular risk in RA, as mentioned previously [6]. Sulfasalazine may potentially reduce cardiovascular morbidity by inhibition of platelet function. A degree of caution is warranted with leflunomide due to its association with hypertension [7].

Another relevant issue is the use of CSDMARDs in the perioperative period. The most recent guidelines for the perioperative approach to patients undergoing elective total hip or knee arthroplasty advocate continuation of each of the csDMARDs (methotrexate, leflunomide, sulfasalazine and antimalarials), due to a low risk of infections and the drugs' beneficial impact on decreasing the risk of post-operative flares [62].

Although these guidelines may serve as a valuable step forward towards harmonization of the perioperative therapeutic approach, it is still not clear to what extent they can be extrapolated to "less sterile" settings such as emergency and abdominal surgery. In the latter circumstances, the more cautious approach accepted by some authorities to withhold methotrexate and leflunomide may be justified.

\section{Conclusions}

Despite the current therapeutic (and pharmaceutical) interest being focused primarily on targeted agents, cSDMARDs still remain the most commonly prescribed drugs in rheumatoid arthritis.

The reason for this is that they are always part of the first treatment strategy and, if not contraindicated, they continue to play an adjunct role with other medications in further attempts (treatment strategies) to achieve remission or low disease activity.

From a public health and global perspective, the low cost of cSDMARDs, or, alternatively, high cost of targeted therapy, makes csDMARDs and their combinations a reasonable and sometimes the only available therapeutic option, especially in lower to medium income countries.

The authors declare no conflict of interests.

\section{References}

1. Nell VP, Machold KP, Eberl G, et al. Benefit of very early referral and very early therapy with disease-modifying anti-rheumatic drugs in patients with early rheumatoid arthritis. Rheumatology (Oxford) 2004; 43: 906-914, DOI: 10.1093/rheumatology/keh199.

2. Bijlsma JW. Disease control with glucocorticoid therapy in rheumatoid arthritis. Rheumatology (Oxford) 2012; 51 (Suppl 4): iv9-iv13, DOI: 10.1093/rheumatology/kes086. 
3. Smolen JS, van der Heijde D, Machold KP, et al. Proposal for a new nomenclature of disease-modifying antirheumatic drugs. Ann Rheum Dis 2014; 73: 3-5, DOI: 10.1136/annrheumdis-2013-204317.

4. Pincus T, Yazici Y, Sokka T, et al. Methotrexate as the "anchor drug" for the treatment of early rheumatoid arthritis. Clin Exp Rheumatol 2003; 21 (5 Suppl 31): 179-185.

5. Smolen JS, Landewé R, Bijlsma J, et al. EULAR recommendations for the management of rheumatoid arthritis with synthetic and biological disease-modifying antirheumatic drugs: 2019 update. Ann Rheum Dis 2020; 79: 685-699, DOI: 10.1136/ annrheumdis-2019-216655.

6. Rawla P. Cardiac and vascular complications in rheumatoid arthritis. Reumatologia 2019; 57: 27-36, DOI: 10.5114/ reum.2019.83236.

7. Chan ES, Cronstein BN. Mechanisms of action of methotrexate. Bull Hosp Jt Dis 2013; 71 (Suppl 1): 5-8.

8. Schiff MH, Jaffe JS, Freundlich B. Head-to-head, randomised crossover study of oral versus subcutaneous methotrexate in patients with rheumatoid arthritis: drug-exposure limitations of oral methotrexate at doses $\geq 15 \mathrm{mg}$ may be overcome with subcutaneous administration. Ann Rheum Dis 2014; 73: 15491551, DOI: 10.1136/annrheumdis-2014-205228.

9. van Roon EN, van de Laar MA. Methotrexate bioavailability. Clin Exp Rheumatol 2010; 28 (5 Suppl 61): 27-32.

10. Bianchi G, Caporali R, Todoerti M, Mattana P. Methotrexate and rheumatoid arthritis: current evidence regarding subcutaneous versus oral routes of administration. Adv Ther 2016; 33: 369-378, DOI: 10.1007/s12325-016-0295-8.

11. Smolen JS, Aletaha D. Rheumatoid arthritis therapy reapprais al: strategies, opportunities and challenges. Nat Rev Rheumatol 2015; 11: 276-289, DOI: 10.1038/nrrheum.2015.8.

12. Jones $G$, Sebba $A, G u$ J, et al. Comparison of tocilizumab monotherapy versus methotrexate monotherapy in patients with moderate to severe rheumatoid arthritis: the AMBITION study. Ann Rheum Dis 2010; 69: 88-96, DOI: 10.1136/ard. 2008.105197

13. Fleischmann RM, Huizinga TW, Kavanaugh AF, et al. Efficacy of tofacitinib monotherapy in methotrexate-naive patients with early or established rheumatoid arthritis. RMD Open 2016; 2 e000262, DOI: 10.1136/rmdopen-2016-000262.

14. Durán J, Bockorny M, Dalal D, et al. Methotrexate dosage as a source of bias in biological trials in rheumatoid arthritis: a systematic review. Ann Rheum Dis 2016; 75: 1595-1598, DOI: 10.1136/annrheumdis-2016-209383.

15. Gaujoux-Viala C, Smolen JS, Landewé R, et al. Current evidence for the management of rheumatoid arthritis with synthetic disease-modifying antirheumatic drugs: a systematic literature review informing the EULAR recommendations for the management of rheumatoid arthritis. Ann Rheum Dis 2010; 69: 1004-1009, DOI: 10.1136/ard.2009.127225.

16. Cannella AC, O'Dell JR. Traditional DMARDs: methotrexate, leflunomide, sulfasalazine, hydroxychloroquine and combination therapies. In: Kelley and Firestein's textbook of rheumatology. Firestein GS, Budd RC, Gabriel SE, McInnes IB, O’Dell JR (eds.). 10 ${ }^{\text {th }}$ ed. Elsevier, Philadelphia 2017: 958-982.

17. Saag KG, Teng GG, Patkar NM, et al. American College of Rheumatology 2008 recommendations for the use of nonbio- logic and biologic disease-modifying antirheumatic drugs in rheumatoid arthritis. Arthritis Rheum 2008; 59: 762-784, DOI: 10.1002/art.23721.

18. Götestam Skorpen C, Hoeltzenbein M, Tincani A, et al. The EULAR points to consider for use of antirheumatic drugs before pregnancy, and during pregnancy and lactation. Ann Rheum Dis 2016; 75: 795-810, DOI: 10.1136/annrheumdis-2015-208840.

19. Salliot C, van der Heijde D. Long-term safety of methotrexate monotherapy in patients with rheumatoid arthritis: a systematic literature research. Ann Rheum Dis 2009; 68: 1100-1104, DOI: 10.1136/ard.2008.093690.

20. Johnsen AK, Weinblatt ME. Methotrexate. In: Rheumatology. Hochberg MC, Silman AJ, Smolen JS, Weinblatt ME, Weisman MH (eds.). $6^{\text {th }}$ ed. Elsevier/Mosby, Philadelphia 2015: 443-458.

21. Smolen JS, Graninger WB, Emery P. Leflunomide, a new disease-modifying anti-rheumatic drug and the never ending rheumatoid arthritis story. Rheumatology (Oxford) 2000; 39: 689-692, DOI: 10.1093/rheumatology/39.7.689.

22. Breedveld FC, Dayer JM. Leflunomide: mode of action in the treatment of rheumatoid arthritis. Ann Rheum Dis 2000; 59 : 841-849, DOI: 10.1136/ard.59.11.841.

23. Kellner H, Bornholdt $\mathrm{K}$, Hein G. Leflunomide in the treatment of patients with early rheumatoid arthritis - results of a prospective non-interventional study. Clin Rheumatol 2010; 29: 913-920, DOI: 10.1007/s10067-010-1425-3.

24. Cutolo M, Bolosiu H, Perdriset G, for the LEADER Study Group. Efficacy and safety of leflunomide in DMARD-naive patients with early rheumatoid arthritis: comparison of a loading and a fixed-dose regimen. Rheumatology (Oxford) 2013; 52: 11321140, DOI: 10.1093/rheumatology/kes321.

25. Rozman B. Clinical pharmacokinetics of leflunomide. Clin Pharmacokinet 2002; 41: 421-430, DOI: 10.2165/00003088200241060-00003.

26. Haraoui B. Leflunomide. In: Rheumatology. $6^{\text {th }}$ ed. Hochberg MC, Silman AJ, Smolen JS, Weinblatt ME, Weisman MH (ed.). Elsevier/Mosby, Philadelphia 2015: 451-458.

27. Bérard A, Zhao JP, Shui I, Colilla S. Leflunomide use during pregnancy and the risk of adverse pregnancy outcomes. Ann Rheum Dis 2018; 77: 500-509, DOI: 10.1136/annrheumdis-2017-212078.

28. Aletaha D, Stamm T, Kapral T, et al. Survival and effectiveness of leflunomide compared with methotrexate and sulfasalazine in rheumatoid arthritis: a matched observational study. Ann Rheum Dis 2003; 62: 944-951, DOI: 10.1136/ard.62.10.944.

29. Lie E, Uhlig T, van der Heijde D, et al. Effectiveness of sulfasalazine and methotrexate in 1102 DMARD-naive patients with early RA. Rheumatology (Oxford) 2012; 51: 670-678, DOI: 10.1093/rheumatology/ker356.

30. Box SA, Pullar T. Sulphasalazine in the treatment of rheumatoid arthritis. Br J Rheumatol 1997; 36: 382-386, DOI: 10.1093/ rheumatology/36.3.382.

31. Smolen JS, Landewé R, Bijlsma J, et al. EULAR recommendations for the management of rheumatoid arthritis with synthetic and biological disease-modifying antirheumatic drugs: 2016 update. Ann Rheum Dis 2017; 76: 960-977, DOI: 10.1136/ annrheumdis-2016-210715. 
32. Amos RS, Pullar T, Bax DE, et al. Sulphasalazine for rheumatoid arthritis: toxicity in 774 patients monitored for one to 11 years. Br Med J (Clin Res Ed) 1986; 293: 420-423, DOI: 10.1136/bmj.293.6544.420

33. Upchurch KS, Kay J. Evolution of treatment for rheumatoid arthritis. Rheumatology (Oxford) 2012; 51 (Suppl 6): vi28-vi36, DOI: 10.1093/rheumatology/kes278.

34. Suarez-Almazor ME, Belseck E, Shea B, et al. Antimalarials for treating rheumatoid arthritis. Cochrane Database Syst Rev 2000; (4): CD000959, DOI: 10.1002/14651858.CD000959.

35. Bykerk VP. Nonimmunosuppressive disease-modifying antirheumatic drugs. In: Rheumatology. Hochberg MC, Silman AJ, Smolen JS, Weinblatt ME, Weisman MH (eds.). $6^{\text {th }}$ ed. Elsevier/ Mosby, Philadelphia 2015: 434-442.

36. Rainsford KD, Parke AL, Clifford-Rashotte M, Kean WF. Therapy and pharmacological properties of hydroxychloroquine and chloroquine in treatment of systemic lupus erythematosus, rheumatoid arthritis and related diseases. Inflammopharmacology 2015; 23: 231-269, DOI: 10.1007/s10787-015-0239-y.

37. Costedoat-Chalumeau N, Dunogué B, Morel N, et al. Hydroxychloroquine: a multifaceted treatment in lupus. Presse Med 2014; 43 (6 Pt 2): e167-e180, DOI: 10.1016/j.lpm.2014.03.007.

38. Lee SJ, Silverman E, Bargman JM. The role of antimalarial agents in the treatment of SLE and lupus nephritis. Nat Rev Nephrol 2011; 7: 718-729, DOI: 10.1038/nrneph.2011.150.

39. Rempenault C, Combe B, Barnetche T, et al. Metabolic and cardiovascular benefits of hydroxychloroquine in patients with rheumatoid arthritis: a systematic review and meta-analysis. Ann Rheum Dis 2018; 77: 98-103, DOI: 10.1136/annrheumdis-2017-211836.

40. Marmor MF, Kellner U, Lai TYY, et al. Recommendations on screening for chloroquine and hydroxychloroquine retinopathy (2016 revision). Ophthalmology 2016; 123: 1386-1394, DOI: 10.1016/j.ophtha.2016.01.058.

41. Goekoop-Ruiterman YP, De Vries-Bouwstra JK, Allaart CF, et al. Clinical and radiographic outcomes of four different treatment strategies in patients with early rheumatoid arthritis (the BeSt study): a randomized, controlled trial. Arthritis Rheum 2005; 52: 3381-3390, DOI: 10.1002/art.21405.

42. Singh JA, Saag KG, Bridges SL, et al. 2015 American College of Rheumatology guideline for the treatment of rheumatoid arthritis. Arthritis Rheumatol 2016; 68: 1-26, DOI: 10.1002/ art.39480.

43. Sethi MK, O’Dell JR. Combination conventional DMARDs compared to biologicals: what is the evidence? Curr Opin Rheumatol 2015; 27: 183-188, DOI: 10.1097/BOR.0000000000000153.

44. Zanwar A, Ahmed S, Misra D, et al. Recent evidence comparing combination of conventional synthetic disease-modifying antirheumatic drugs with biologic disease-modifying antirheumatic drugs in rheumatoid arthritis. Indian J Rheumatol 2017; 12: 104, DOI: 10.4103/injr.injr_37_17.

45. Hazlewood GS, Barnabe C, Tomlinson G, et al. Methotrexate monotherapy and methotrexate combination therapy with traditional and biologic disease modifying antirheumatic drugs for rheumatoid arthritis: abridged Cochrane systematic review and network meta-analysis. BMJ 2016; 353: i1777, DOI: 10.1136/bmj.i1777.
46. Fleischmann R, Tongbram V, van Vollenhoven R, et al. Systematic review and network meta-analysis of the efficacy and safety of tumour necrosis factor inhibitor-methotrexate combination therapy versus triple therapy in rheumatoid arthritis. RMD Open 2017; 3: e000371, DOI: 10.1136/rmdopen2016-000371.

47. Smolen JS, Landewé R, Breedveld FC, et al. EULAR recommendations for the management of rheumatoid arthritis with synthetic and biological disease-modifying antirheumatic drugs: 2013 update. Ann Rheum Dis 2014; 73: 492-509, DOI: 10.1136/ annrheumdis-2013-204573.

48. Singh JA, Furst DE, Bharat A, et al. 2012 Update of the 2008 American College of Rheumatology recommendations for the use of disease-modifying antirheumatic drugs and biologic agents in the treatment of rheumatoid arthritis: 2012 ACR RA Treatment Recommendations. Arthritis Care Res 2012; 64: 625-639, DOI: 10.1002/acr.21641.

49. Bergstra SA, Branco JC, Vega-Morales D, et al. Inequity in access to bDMARD care and how it influences disease outcomes across countries worldwide: results from the METEOR-registry. Ann Rheum Dis 2018; 77: 1413-1420, DOI: 10.1136/annrheumdis-2018-213289.

50. Erhardt DP, Cannon GW, Teng C-C, et al. Persistence rates in patients with rheumatoid arthritis treated with triple therapy and adverse drug events associated with sulfasalazine. Arthritis Care Res 2019; 71: 1326-1335, DOI: 10.1002/acr.23759.

51. Kremer JM, Genovese MC, Cannon GW, et al. Concomitant leflunomide therapy in patients with active rheumatoid arthritis despite stable doses of methotrexate. A randomized, double-blind, placebo-controlled trial. Ann Intern Med 2002; 137: 726-733, DOI: 10.7326/0003-4819-137-9-200211050-00007.

52. Castrejón I, Gibson KA, Pincus T. Efficacy and safety of methotrexate in combination with other non-biologic disease-modifying antirheumatic drugs (DMARDs) in treatment of rheumatoid arthritis. Bull Hosp Jt Dis (2013) 2013; (71 Suppl 1): 20-28.

53. Faarvang KL, Egsmose C, Kryger P, et al. Hydroxychloroquine and sulphasalazine alone and in combination in rheumatoid arthritis: a randomised double blind trial. Ann Rheum Dis 1993; 52: 711-715, DOI:10.1136/ard.52.10.711.

54. Register KA, Cannella AC, Mikuls TR, O’Dell JR. Leflunomide, Sulfasalazine and Hydroxychloroquine for Rheumatoid Arthritis: Efficacious but Poorly Tolerated [abstract]. Arthritis Rheumatol 2016; 68 (Suppl 10).

55. Carmichael SJ, Beal J, Day RO, Tett SE. Combination therapy with methotrexate and hydroxychloroquine for rheumatoid arthritis increases exposure to methotrexate. J Rheumatol 2002; 29: 2077-2083.

56. Emery P, Pope JE, Kruger K, et al. Efficacy of monotherapy with biologics and JAK inhibitors for the treatment of rheumatoid arthritis: a systematic review. Adv Ther 2018; 35: 1535-1563, DOI: 10.1007/s12325-018-0757-2.

57. Fleischmann R, Mysler E, Hall S, et al. Efficacy and safety of tofacitinib monotherapy, tofacitinib with methotrexate, and adalimumab with methotrexate in patients with rheumatoid arthritis (ORAL Strategy): a phase 3b/4, double-blind, head-tohead, randomized controlled trial. Lancet 2017; 390: 457-468, DOI: 10.1016/S0140-6736(17)31618-5. 
58. Gremese E, Alivernini S, Tolusso B, et al. JAK inhibition by methotrexate (and csDMARDs) may explain clinical efficacy as monotherapy and combination therapy. J Leukoc Biol 2019; 106: 1063-1068, DOI: 10.1002/JLB.5RU0519-145R.

59. Jarek $M$. Rheumatic disorders in patients on dialysis. In: Rheumatology secrets, ed. West SG. $3^{\text {rd }}$ ed. Elsevier/Mosby, Philadelphia 2015: 571-576.

60. Bergner R, Peters L, Schmitt V, Löffler C. Leflunomide in dialysis patients with rheumatoid arthritis - a pharmacokinetic study. Clin Rheumatol 2013; 32: 267-270, DOI: 10.1007/s10067012-2122-1.
61. West S. Rheumatic manifestations of gastrointestinal and hepatobiliary diseases. In: Rheumatology secrets. West SG (ed.). $3^{\text {rd }}$ ed. Elsevier/Mosby, Philadelphia 2015: 268-275.

62. Goodman SM, Springer B, Guyatt G, et al. 2017 American College of Rheumatology/American Association of Hip and Knee Surgeons guideline for the perioperative management of antirheumatic medication in patients with rheumatic diseases undergoing elective total hip or total knee arthroplasty: ACR/ AAHKS Guideline for Perioperative Management. Arthritis Rheumatol 2017; 69: 1538-1551, DOI: 10.1002/art.40149. 